\title{
A high throughout semi-quantification method for screening organic contaminants in river sediments
}

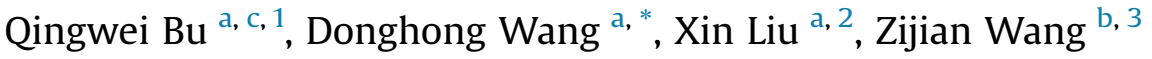 \\ ${ }^{a}$ Key Laboratory of Aquatic Science and Technology, Research Center for Eco-Environmental Sciences, Chinese Academy of Sciences, P.O. Box 2871, Beijing \\ 100085, PR China \\ ${ }^{\mathrm{b}}$ State Key Laboratory of Environmental Aquatic Chemistry, Research Center for Eco-Environmental Sciences, Chinese Academy of Sciences, P.O. Box 2871, \\ Beijing 100085, PR China \\ ' School of Environment, Tsinghua University, Beijing 100084, PR China
}

\section{A R T I C L E I N F O}

\section{Article history:}

Received 22 November 2012

Received in revised form

29 April 2014

Accepted 12 May 2014

Available online 3 June 2014

\section{Keywords:}

High throughout screening

Semi-quantification

Non-target analysis

Watershed management

River sediments

\begin{abstract}
A B S T R A C T
A high throughout semi-quantification method for screening nearly 900 organic contaminants (OCs) in river sediments has been developed. For most OCs tested, concentrations calculated from the proposed semi-quantification method deviated from actual values by a factor of 4 . The overall recovery tests indicated that most OCs can be successfully extracted from sediments with recovery rates from 84.1 to 128.6\%. To demonstrate the effectiveness of our method towards OC quantification, we screened OCs from sediments collected from the Haihe River basin. Seventy unregulated OCs (including pesticides, flame retardants, PPCPs, etc.) were identified and quantified at concentrations up to $2600 \mathrm{ng} / \mathrm{g}$ from 24 sediment samples. From these results, it is confirmed that the developed method is a useful way to fulfill a comprehensive analysis of OCs in sediments and would be valuable for the identification and prioritization of priority pollutants in watershed management.
\end{abstract}

๑) 2014 Elsevier Ltd. All rights reserved.

\section{Introduction}

Large number of organic chemicals have been produced and released into the environment worldwide and the number is increasing (Bu et al., 2013). Adverse ecological and human health effects have been observed for these organic contaminants (OCs) (Long et al., 1995; Sharpe, 2001; Feron et al., 2002; Sharpe and Irvine, 2004). It is thus of fundamental importance to determine OC concentrations in various environmental matrices which is essential for causation validation in dose-effect analysis. However, the number of environmentally monitored OCs is limited and is not enough to assess ecological and human health risks posed by OCs in general. Currently, analytical methods (Kolpin et al., 2002) required to assess OC contamination levels are time-consuming and costly. Hence high throughout screening of samples offers attractive prospects for environmental managers.

Several methods for comprehensive analysis of OCs in the environment have been reported. For example, Gómez et al. (2009)

\footnotetext{
* Corresponding author. Tel.: +86106284 9197; fax: +861062849140.

E-mail addresses: qingweibu@tsinghua.edu.cn (Q. Bu), dhwang@rcees.ac.cn

(D. Wang), meteor0982@163.com (X. Liu), wangzj@rcees.ac.cn (Z. Wang).

1 Tel.: +86106277 1637 .

2 Tel.: +861062849107.

3 Tel.: +861062849140.
}

introduced a novel method for simultaneous analysis of 934 OCs in water. Kadokami et al. (2005) developed a comprehensive screening method for nearly 700 OCs in environmental samples and applied to nearly 1000 OCs recently (Kadokami et al., 2012). In our previous studies, a broad spectrum of 50 phenols were screened using retention time locking (RTL) technology and deconvolution reporting software (DRS) (Zhong et al., 2010). Further, we established a qualitative screening method for 1093 contaminants in water and applied it for OC screening in water of the Danjiangkou reservoir (Bu et al., 2014). Our previous methods are sufficient for qualitative screening, but are insufficient for quantitative analysis. Previously a single random internal standard was used to quantify all OCs (Kadokami et al., 2005, 2012) and the accuracy of quantitative analysis was seldom reported. This may lead to bias in quantification results as response factors (RFs) of chemicals differ on mass selective detector (MSD).

In the present study, a set of quantification internal standards (QISs) was proposed to estimate concentrations of 847 OCs in river sediments. All 847 OCs were selected from our previous database (Bu et al., 2014) by excluding OCs that can be routinely monitored (e.g. polycyclic aromatic hydrocarbons). To facilitate this process, sample extraction and clean-up procedures were optimized for OC analysis in river sediments; then the accuracy of semiquantification was evaluated using QISs; and finally the 
effectiveness our new method was validated. The overall goal of this study is to develop a novel high throughout, semiquantification method for OC screening in river sediments.

\section{Materials and methods}

\subsection{The database}

Our database contains 847 OCs that are relevant to China, including current in-use and legacy pesticides, traditional persistent organic pollutants such as co-planar polychlorinated biphenyls (PCBs), emerging contaminants such as pharmaceuticals and personal care products (PPCPs), fire retardants, and new persistent organic pollutants (e.g. chlordecone and pentachlorobenzene). All of which are suitable for analysis by gas chromatography-mass selective detector (GC-MSD) (Pang et al., 2006).

\subsection{Chemicals and materials}

All solvents were HPLC grade (J.T. Baker, Phillipsburg, NJ, USA). QISs were purchased from AccuStandard Inc. (New Haven, Connecticut, USA). Acidic alumina ( $2 \mathrm{~g}, 6 \mathrm{~mL})$, basic alumina $(2 \mathrm{~g}, 6 \mathrm{~mL})$, neutral alumina $(2 \mathrm{~g}, 6 \mathrm{~mL})$, silica $(500 \mathrm{mg}, 6 \mathrm{~mL})$ and Florisil (500 mg, $6 \mathrm{~mL}$ ) cartridges were obtained from Supelco (Bellefonte, Pennsylvania, USA). All glassware was washed with acetone and water, soaked overnight in concentrated sulfuric acid containing 5\% $\mathrm{K}_{2} \mathrm{Cr}_{2} \mathrm{O}_{4}$ solution, washed with distilled water and baked at $550-600{ }^{\circ} \mathrm{C}$ for five hours.

\subsection{Analytical procedure}

OCs were extracted from freeze-dried sediments $(5 \mathrm{~g})$ with dichloromethane/acetone $(1: 1, v / v)$ using an accelerated solvent extraction (ASE, Dionex ASE350, Dionex, Sunnyvale, California, USA) system, at $130^{\circ} \mathrm{C}$ and $1500 \mathrm{psi}$, with two extraction cycles. The static time for each cycle was 5 min and the cell was flushed with $100 \%$ of the cell volume at the end of the extraction. The extracts were cleaned-up by the gel permeation chromatography (GPC), followed by solid phase extraction (SPE) with the adsorption chromatography.

GPC clean-up was conducted on a Bio-Beads SX3 column (BioRad Laboratories, Hercules, California, USA) using the following conditions: mobile phase, cyclohexane/ethyl acetate $(1: 1, \mathrm{v}: \mathrm{v})$; flow rate, $4.7 \mathrm{ml} / \mathrm{min}$; detection wavelength, $254 \mathrm{~nm}$; commenced collection time, $9 \mathrm{~min}$; stopped collection time, $17 \mathrm{~min}$. Thereafter, the solvent was changed to hexane in approximately $1 \mathrm{ml}$. The hexane concentrate was applied to SPE with a Florisil cartridge, which was pre-conditioned by using $6 \mathrm{ml}$ of methanol and $6 \mathrm{ml}$ of hexane. The cartridge was eluted by $5 \mathrm{ml}$ of mixture of dichloromethane/acetone $(1: 1, \mathrm{v}: \mathrm{v})$. The cleaned extracts were evaporated under a gentle stream of nitrogen and analyzed by GC-MSD.

\subsection{GC-MSD analysis}

An Agilent 6890N-5975D GC-MSD (Agilent Technologies, Santa Clara, California, USA) with a DB-5 capillary column $(30 \mathrm{~m} \times 0.25 \mathrm{~mm}$ i.d. $\times 0.25 \mu \mathrm{m}$ film thickness, Agilent J\&W Scientific) was used for sample analysis. High purity helium (99.9999\%) was used as the carrier gas. RTL, data acquisition and processing were performed using Agilent MSD ChemStation Software (Version E.0200.493). Retention time of fluoranthene was locked at 20.839 min during analysis by adjusting the column pressure. The oven temperature was held at $70^{\circ} \mathrm{C}$ for $2 \mathrm{~min}$, raised to $150^{\circ} \mathrm{C}$ at $25^{\circ} \mathrm{C} / \mathrm{min}$, then raised to $200^{\circ} \mathrm{C}$ at $3{ }^{\circ} \mathrm{C} / \mathrm{min}$, then raised to $280{ }^{\circ} \mathrm{C}$ at $8{ }^{\circ} \mathrm{C} / \mathrm{min}$ and held at $280{ }^{\circ} \mathrm{C}$ for $15 \mathrm{~min}$. The inlet and
MS transfer line temperatures were both set at $250{ }^{\circ} \mathrm{C}$, and the ion source temperature was $230^{\circ} \mathrm{C}$. MSD was operated in full scan mode from $\mathrm{m} / \mathrm{z} 50$ to 700 .

All data were analyzed using DRS. A positive identification was confirmed when the following criteria were met: the automated mass spectral deconvolution and identification system match values were higher than $60 \%$ and the retention time differences between the expected and observed values were less than $10 \mathrm{~s}$. The extracted spectrum was also reverse-matched with the National Institute of Standards and Technology library. Quantification was conducted by comparing their peak areas of identified contaminants to the respective QISs.

\subsection{Collection of river sediments}

Sediment samples used for performance validation were collected at 24 sites (Fig. S1) from different zones of the Haihe River basin using a grab sampler. All samples were immediately transported to the laboratory and stored at $-20^{\circ} \mathrm{C}$ until analysis.

\section{Results and discussion}

\subsection{Optimization of sample pretreatment}

Although several extraction methods have been reported for solid samples, such as soxthlet extraction and ultrasonic extraction, ASE was chosen in the present study due to high extraction efficiency of various OCs from different matrices (Bandh et al., 2000; Ding and Fann, 2000; Windal et al., 2000; Li et al., 2007). Dichloromethane and acetone were used as extraction solvents because they are suitable for a wide range of OCs (Kadokami et al., 2012).

In clean-up procedure, GPC combined with SPE was employed. GPC is generally used to separate smaller molecules from the larger ones, and can be used to purify a broad range of analytes, both polar and non-polar (USEPA, 1994). The commenced collection time is optimized by using coin oil (as the marker of interfering substances) and tralomethrin (as the marker of high molecular weight targets). Strong response was found between 5 and $9.2 \mathrm{~min}$, with peak at 7.1 min corresponding to coin oil. Tralomethrin was eluted between 9.5 and $13.5 \mathrm{~min}$, with peak value at $11.9 \mathrm{~min}$. Therefore commenced collection time was chosen at $9 \mathrm{~min}$. To determine the stopped collection time, elution curves of four PCBs (PCB-28, PCB-41, PCB138 and $\mathrm{PCB}-209$, representing contaminants with different molecular weights) were profiled in Fig. S2. All selected PCBs started to elute at 11 min. PCB-209 and PCB-138, which have greater molecular weights, completely eluted within 11-15 min, while complete elution of PCB-41 and PCB-28 falls between 11 and 16 min. To validate the stopped collection time, 2,4-dichlorophenol (with molecular weight of 163) was used as the marker of low molecular weight targets and was completely eluted at 16 min on GPC column. From above results, we conservatively inferred that all target contaminants eluted from GPC columns between 9 and $17 \mathrm{~min}$. Good recoveries (91.8-106.3\%) were obtained for all four PCBs. Therefore GPC clean-up condition has been decided to be: clean-up column, Bio-Beads SX3 (300 mm $\times 25 \mathrm{~mm}$ i.d.); mobile phase, cyclohexane/ ethyl acetate $(1: 1, \mathrm{v} / \mathrm{v})$; flow rate, $4.7 \mathrm{ml} / \mathrm{min}$; detection wavelength, $254 \mathrm{~nm}$; the commenced collection time, $9 \mathrm{~min}$; the stopped collection time, $17 \mathrm{~min}$; the collection volume, $37.6 \mathrm{ml}$.

For adsorption chromatography, five widely used adsorbents were tested, including silica, Florisil, acid alumina, neutral alumina and basic alumina. The detailed optimization procedure was described in SI-1. For each adsorbent, elution solvents were optimized for 74 OCs (Table S1). Considering the wide spectrum of OCs analyzed using this method, we performed a principal component analysis, which offers an integrative indicator for OC recovery. In 
addition, enhanced OC recovery was observed by increasing polarity and/or amounts of elution solvents for each adsorbent (Fig. S3, Tables S2 and S3), which was in accordance with previous observations (Ahn et al., 2007; Turlington and McDow, 2010). However, pronounced matrix effects were observed for polar elution solvents. Therefore minimal amount of elution solvents with adequate polarity that produces $60 \%$ or higher OC recovery was used. Elution condition was determined to be: $7 \mathrm{ml}$ of dichloromethane/acetone (9:1, v:v) for silica; $5 \mathrm{ml}$ of dichloromethane/acetone (1:1, v:v) for Florisil; $5 \mathrm{ml}$ of dichloromethane/ acetone $(1: 1, \mathrm{v}: \mathrm{v})$ for acid alumina; $5 \mathrm{ml}$ of dichloromethane/ methanol (9:1, v:v) for neutral alumina; and $5 \mathrm{ml}$ of dichloromethane/methanol (9:1, v:v) for basic alumina.

Although elution patterns are similar for all five adsorbents (Tables S2 and S3), Florisil eluent has shown least turbidity (Fig. S4).
From these results, the clean-up chromatography for OCs in river sediments was decided to be a combination of GPC and Florisil SPE. Although matrix effect may not be completely avoided by our optimized clean-up method, it is acceptable for high throughout screening of OCs with a broad range of physio-chemical properties.

\subsection{Accuracy of semi-quantification}

In this study, all 847 OCs screened were categorized into 14 groups according to their chemical properties by which QIS is assigned (Table S4).

The accuracy of semi-quantification was tested by analyzing a standard solution containing $1 \mu \mathrm{g} / \mathrm{mL}$ of selected OCs. The ratios of measured to theoretical concentrations (M/Ts) of different OCs were calculated and listed in Table 1. For most OCs tested, the calculated

Table 1

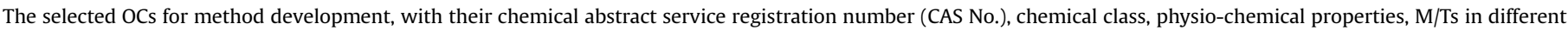
samples, and recoveries using the high throughout analytical method presented.

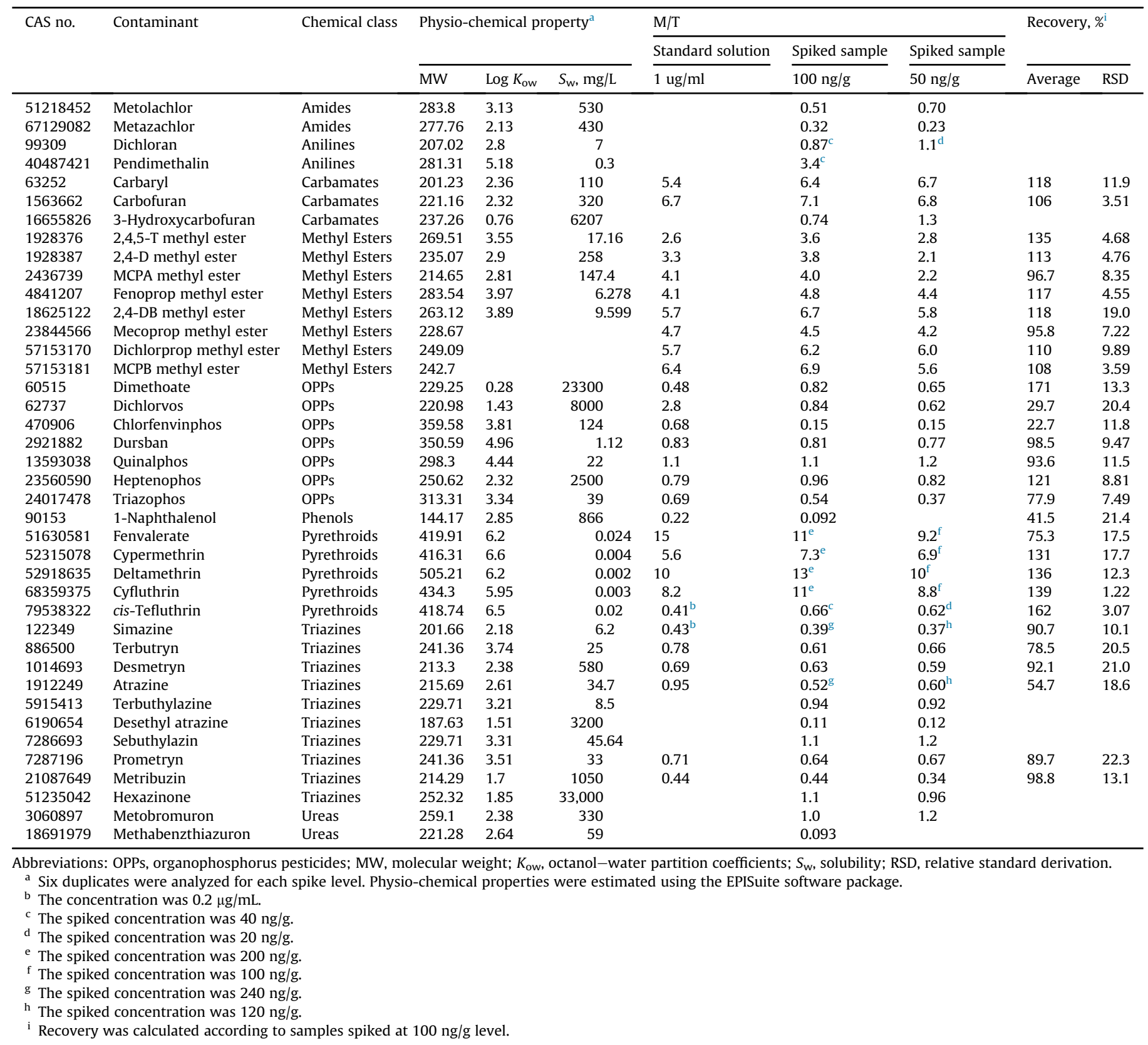


concentrations usually differed from actual measurements by a factor of 4 . However our estimates imposed uncertainty in factors of 5-10 for two exceptional cases: pyrethroids and carbamates.

The over- or under-estimated concentrations by our QISs are due to different RFs between targets and the respective QIS on MSD. In electron ionization mode, RFs of OCs were affected by ion transmission, fractional ion abundance, ionization cross section, and compound molecular weights (Sauter et al., 1986). And these are exactly factors considered in the selection of QISs in our study. The M/T ratios showed that RFs of tested OCs were comparable to their respective QIS, which was in agreement with Sauter et al. (1983). They reported comparable RFs between chemicals within the same chemical class. Lundgren et al. (2004) determined RFs of 87 polychlorinated dibenzofurans and found that the maximum to minimum RF ratio was close to 2 for all homologues. All these results demonstrated the potential of using QISs to semi-quantify concentrations of large number of OCs in the high throughout screening analysis.

\subsection{Overall recovery tests}

The overall recovery tests were run to confirm the performance of our proposed method. Sediment with a high organic matter $(40.3 \mathrm{~g} / \mathrm{kg}$ ) was spiked by a series of OCs (from nine chemical classes with varying properties) at two concentration levels in a $100 \mathrm{ml}$ container. The container was capped immediately and hand shaken for at least $10 \mathrm{~min}$ after spiking. The prepared spiked samples were stored at room temperature at dark for at least 10 days before extraction.
The recovery rates of tested OCs are listed in Table 1. Acceptable recovery rates were obtained, on average, for the whole analytical procedure. The $\mathrm{M} / \mathrm{Ts}$ of OCs in the spiked samples and in the standard solution were comparable (Table 1 ), indicating the satisfactory recoveries. The average recoveries for methyl esters, pyrethroids, triazines and organophosphorus pesticides (OPPs) were $111.6 \%, 128.6 \%, 84.1 \%$ and $87.8 \%$, respectively. The procedure can, therefore, be used to determine a series of OCs with varying properties. Lower recoveries were found for some OPPs due to the loss during the evaporation steps (Barranco et al., 2003), the width of the GPC fractionating window (Navarro et al., 2006), and/or matrix effects. In addition, OPPs are prone to thermal degradation during analysis. Albeit this, overall recoveries of the tested OCs ranged from 84.1 to $128.6 \%$ (Table 1), indicating that the developed screening method can analyze most OCs included in our database.

\subsection{Application to actual sediments}

In order to confirm the effectiveness of our high throughout method, we analyzed 24 sediment samples collected from the Haihe River basin. Seventy OCs were identified from sediment samples, and 17 OCs were detected in more than $25 \%$ of sampling sites (Tables 2 and S5).

In general, OC concentrations increased from west to east of the Haihe River basin, such trend can be explained by the intensive agricultural and industrial activities in the corresponding area. Bird repellents 9,10-anthraquinone and biphenyl (a microbiocide) were detected in all sediment samples, with concentrations of 2.3-180 ng/g and 3.8-44 ng/g, respectively. Benzophenone, benzyl

Table 2

Semi-quantitative concentrations of OCs in river sediments collected from the Haihe River basin.

\begin{tabular}{|c|c|c|c|c|c|c|c|c|}
\hline \multirow[t]{2}{*}{ CAS no. } & \multirow[t]{2}{*}{ Contaminant } & \multirow[t]{2}{*}{ Usage } & \multirow{2}{*}{$\begin{array}{l}\text { Frequency } \\
(n=24)\end{array}$} & \multicolumn{5}{|c|}{ Concentration level, ng/g } \\
\hline & & & & $\begin{array}{l}\text { West } \\
(n=5)\end{array}$ & $\begin{array}{l}\text { East } \\
(n=6)\end{array}$ & $\begin{array}{l}\text { Center } \\
(n=6)\end{array}$ & $\begin{array}{l}\text { North } \\
(n=5)\end{array}$ & $\begin{array}{l}\text { South } \\
(n=2)\end{array}$ \\
\hline 84651 & 9,10-Anthraquinone & Bird repellent & $100 \%$ & $\begin{array}{l}36 \\
(26-69)^{\mathrm{a}}\end{array}$ & $\begin{array}{l}52 \\
(2.8-180)\end{array}$ & $\begin{array}{l}12 \\
(2.3-23)\end{array}$ & $\begin{array}{l}21 \\
(5.1-53)\end{array}$ & $\begin{array}{l}13 \\
(11-16)\end{array}$ \\
\hline 92524 & Biphenyl & Microbiocide & $100 \%$ & $\begin{array}{l}16 \\
(6.6-31)\end{array}$ & $\begin{array}{l}14 \\
(4.2-44)\end{array}$ & $\begin{array}{l}13 \\
(6.5-29)\end{array}$ & $\begin{array}{l}12 \\
(5.5-20)\end{array}$ & $\begin{array}{l}4.0 \\
(3.8-4.2)\end{array}$ \\
\hline 119619 & Benzophenone & $\begin{array}{l}\text { Radiation-sensitizing } \\
\text { agent }\end{array}$ & $83 \%$ & $\begin{array}{l}4.5 \\
(n . d-6.8)\end{array}$ & $\begin{array}{l}49 \\
(10-180)\end{array}$ & $\begin{array}{l}15 \\
(\mathrm{n} . \mathrm{d}-28)\end{array}$ & $\begin{array}{l}11 \\
(2.3-22)\end{array}$ & $\begin{array}{l}2.9 \\
(2.0-3.7)\end{array}$ \\
\hline 120514 & Benzyl benzoate & Insect repellent & $79 \%$ & $\begin{array}{l}4.9 \\
(n . d-7.4)\end{array}$ & $\begin{array}{l}7.2 \\
(\mathrm{n} . \mathrm{d}-10)\end{array}$ & $\begin{array}{l}4.2 \\
(0.98-8.9)\end{array}$ & $\begin{array}{l}13 \\
(4.2-21)\end{array}$ & n.d \\
\hline 2941551 & Ethiolate & Herbicide & $79 \%$ & $\begin{array}{l}0.75 \\
(n . d-1.0)\end{array}$ & $\begin{array}{l}870 \\
(n \cdot d-2600)\end{array}$ & $\begin{array}{l}5.1 \\
(\mathrm{n} . \mathrm{d}-8.2)\end{array}$ & $\begin{array}{l}4.0 \\
(1.4-9.2)\end{array}$ & $\begin{array}{l}1.7 \\
(1.1-2.3)\end{array}$ \\
\hline 1918112 & Terbutol & Herbicide & $75 \%$ & $\begin{array}{l}720 \\
(260-1500)\end{array}$ & $\begin{array}{l}1400 \\
(\text { n.d-2100) }\end{array}$ & $\begin{array}{l}580 \\
(\mathrm{n} . \mathrm{d}-970)\end{array}$ & $\begin{array}{l}330 \\
(\mathrm{n} . \mathrm{d}-470)\end{array}$ & $\begin{array}{l}28 \\
(24-32)\end{array}$ \\
\hline 14214325 & Difenoxuron & Herbicide & $75 \%$ & $\begin{array}{l}11 \\
(n . d-13)\end{array}$ & $\begin{array}{l}14 \\
(\mathrm{n} . \mathrm{d}-238)\end{array}$ & $\begin{array}{l}260 \\
(10-1500)\end{array}$ & $\begin{array}{l}44 \\
(0.36-170)\end{array}$ & n.d \\
\hline 122394 & Diphenylamine & $\begin{array}{l}\text { Fungicide and plant } \\
\text { growth regulator }\end{array}$ & $67 \%$ & $\begin{array}{l}140 \\
(28-240)\end{array}$ & $\begin{array}{l}90 \\
(n . d-150)\end{array}$ & $\begin{array}{l}52 \\
(\mathrm{n} . \mathrm{d}-100)\end{array}$ & $\begin{array}{l}56 \\
(n . d-100)\end{array}$ & $\begin{array}{l}18 \\
(\text { n.d-18) }\end{array}$ \\
\hline 126738 & Tributyl phosphate & Flame retardant & $63 \%$ & $\begin{array}{l}71 \\
(n . d-74)\end{array}$ & $\begin{array}{l}89 \\
(n . d-110)\end{array}$ & $\begin{array}{l}52 \\
(n . d-91)\end{array}$ & $\begin{array}{l}180 \\
(61-260)\end{array}$ & n.d \\
\hline 106467 & $p$-Dichlorobenzene & Insect repellent & $58 \%$ & $\begin{array}{l}0.84 \\
(n . d-1.2)\end{array}$ & $\begin{array}{l}1.2 \\
(\mathrm{n} . \mathrm{d}-1.7)\end{array}$ & $\begin{array}{l}1.4 \\
(\mathrm{n} . \mathrm{d}-2.1)\end{array}$ & $\begin{array}{l}1.2 \\
(\mathrm{n} . \mathrm{d}-1.5)\end{array}$ & n.d \\
\hline 90437 & o-Phenylphenol & Disinfectant & $42 \%$ & $\begin{array}{l}16 \\
(9.0-22)\end{array}$ & $\begin{array}{l}19 \\
(\mathrm{n} . \mathrm{d}-33)\end{array}$ & $\begin{array}{l}- \\
(\mathrm{n} . \mathrm{d}-10)\end{array}$ & n.d & n.d \\
\hline 52857 & Famphur & Insect repellent & $38 \%$ & $\begin{array}{l}44 \\
(n . d-74)\end{array}$ & $\begin{array}{l}98 \\
\text { (n.d-280) }\end{array}$ & $\begin{array}{l}19 \\
(n . d-20)\end{array}$ & $\begin{array}{l}1.1 \\
(\mathrm{n} . \mathrm{d}-1.1)\end{array}$ & n.d \\
\hline 85416 & Phthalimide & $\begin{array}{l}\text { Flopel degradation } \\
\text { product }\end{array}$ & $33 \%$ & n.d & $\begin{array}{l}27 \\
(n . d-42)\end{array}$ & n.d-4.8 & $\begin{array}{l}2.4 \\
(\mathrm{n} . \mathrm{d}-2.7)\end{array}$ & $\begin{array}{l}6.0 \\
(5.4-6.6)\end{array}$ \\
\hline 58082 & Caffeine & Stimulant & $33 \%$ & $\begin{array}{l}4.6 \\
(n . d-6.0)\end{array}$ & $\overline{(n . d-2.4)}$ & $\begin{array}{l}2.6 \\
(n . d-3.5)\end{array}$ & $(\mathrm{n} . \mathrm{d}-2.5)$ & n.d \\
\hline 95761 & 3,4-Dichloroaniline & $\begin{array}{l}\text { Diuron degradation } \\
\text { product }\end{array}$ & $29 \%$ & n.d & $\begin{array}{l}53 \\
\text { (n.d-64) }\end{array}$ & n.d & n.d & $\begin{array}{l}190 \\
(0.45-360)\end{array}$ \\
\hline 115968 & $\begin{array}{l}\text { Tris (2-chloroethyl) } \\
\text { phosphate }\end{array}$ & Flame retardant & $29 \%$ & $\begin{array}{l}3.5 \\
(\mathrm{n} . \mathrm{d}-10)\end{array}$ & (n.d-6.2) & $\begin{array}{l}3.5 \\
(\mathrm{n} . \mathrm{d}-7.0)\end{array}$ & n.d & n.d \\
\hline 119904 & o-Dianisidine & $\begin{array}{l}\text { Raw material in } \\
\text { production of dyes }\end{array}$ & $29 \%$ & $\begin{array}{l}7.4 \\
(n . d-15)\end{array}$ & $\begin{array}{l}53 \\
\text { (n.d-100) }\end{array}$ & $\begin{array}{l}- \\
(\text { n.d- }-0.43)\end{array}$ & n.d & n.d \\
\hline
\end{tabular}

\footnotetext{
a Concentration range.
} 
benzoate, ethiolate, terbutol and difenoxuron were found in almost all of the sediments at concentrations up to $2600 \mathrm{ng} / \mathrm{g}$. Two flame retardants (tributyl phosphate and tris (2-chloroethyl) phosphate) and two PPCPs (the disinfectant $o$-phenylphenol and the stimulant caffeine) were detected in more than $30 \%$ of the samples at concentrations up to $260 \mathrm{ng} / \mathrm{g}$ (flame retardants) and $33 \mathrm{ng} / \mathrm{g}$ (PPCPs), respectively. Pesticide degradation products, such as phthalimide, which are generally omitted by target analysis, were also identified (Table 2). A notable result was the detection of 0 -dianisidine, which is a possible human carcinogen, in both the eastern and western zones of the Haihe River basin.

To our knowledge, few newly identified OCs have been reported in previous studies of the Haihe River basin. Heeb et al. (2012) screened 268 micro-pollutants in water samples from the Haihe River system. Caffeine and a diuron metabolite were identified, which is consistent to our results. In addition we have detected prometon, dicamba, and metribuzin, which were absent from Heeb's report. The difference could be due to deviation in sampling sites and matrices. The performance of our high throughout semiquantification method clearly demonstrates its viability for OC screening in sediments. From which OC contamination mapping that is important for environmental managers can be generated.

\section{Conclusions}

A high throughout screening method was developed for screening of large number of OCs in river sediments. Under optimized conditions, this method can simultaneously estimate concentrations of at least 847 OCs. Tests of semi-quantification method demonstrated satisfying accuracy for OC quantification. Recovery tests indicate that most OCs can be successfully extracted from sediments, with recovery rates ranging from 84.1 to $128.6 \%$. This method was applied to screen OCs in sediments collected from the Haihe River basin. Seventy unregulated OCs (including pesticides, flame retardants, PPCPs, etc.) in 24 sediment samples were identified and quantified at concentration up to $2600 \mathrm{ng} / \mathrm{g}$. Our high throughout semi-quantification method offers a framework for screening and semi-quantification of a broad range of OCs in sediments, making it possible to identify and quantify unknown OCs. The method presented here will be valuable for both identification and prioritization of priority pollutants in watershed management.

\section{Acknowledgments}

This study was supported by National High Technology Research and Development Program of China (863 Program) (Grant No. 2012AA06A302), the Ministry of Water Resources' Special Funds for Scientific Research on Public Causes (Grant No. 201201032), and National Natural Science Foundation of China (Grant Nos. 51290283 and 21307068).

\section{Appendix A. Supplementary data}

Supplementary data related to this article can be found at http:// dx.doi.org/10.1016/j.jenvman.2014.05.009.

\section{References}

Ahn, Y.G., Shin, J.H., Kim, H.-Y., Khim, J., Lee, M.-K., Hong, J., 2007. Application of solid-phase extraction coupled with freezing-lipid filtration clean-up for the determination of endocrine-disrupting phenols in fish. Anal. Chim. Acta 603, $67-75$.
Bandh, C., Björklund, E., Mathiasson, L., Näf, C., Zebühr, Y., 2000. Comparison of accelerated solvent extraction and soxhlet extraction for the determination of PCBs in Baltic Sea sediments. Environ. Sci. Technol. 34, 4995-5000.

Barranco, A., Alonso-Salces, R.M., Bakkali, A., Berrueta, L.A., Gallo, B., Vicente, F., Sarobe, M., 2003. Solid-phase clean-up in the liquid chromatographic determination of polycyclic aromatic hydrocarbons in edible oils. J. Chromatogr. A 988, 33-40

Bu, Q., Wang, D., Wang, Z., 2013. Review of screening systems for prioritizing chemical substances. Crit. Rev. Environ. Sci. Technol. 43, 1011-1041.

Bu, Q., Wang, D., Wang, Z., Gu, J., 2014. Identification and ranking of the risky organic contaminants in the source water of the Danjiangkou reservoir. Front. Env. Sci. Eng. 8, 42-53.

Ding, W.-H., Fann, J.C.H., 2000. Application of pressurized liquid extraction followed by gas chromatography-mass spectrometry to determine 4-nonylphenols in sediments. J. Chromatogr. A 866, 79-85.

Feron, V.J., Cassee, F.R., Groten, J.P., van Vliet, P.W., van Zorge, J.A., 2002. International issues on human health effects of exposure to chemical mixtures. Environ. Health Perspect. 110, 893-899.

Gómez, M.J., Gómez-Ramos, M.M., Agüera, A., Mezcua, M., Herrera, S., FernándezAlba, A.R., 2009. A new gas chromatography/mass spectrometry method for the simultaneous analysis of target and non-target organic contaminants in waters. J. Chromatogr. A 1216, 4071-4082.

Heeb, F., Singer, H., Pernet-Coudrier, B., Oi, W., Liu, H., Longrée, P., Müller, B. Berg, M., 2012. Organic micropollutants in rivers downstream of the megacity Beijing: sources and mass fluxes in a large-scale wastewater irrigation system. Environ. Sci. Technol. 46, 8680-8688.

Kadokami, K., Pan, S., Hanh, D.T., Li, X., Miyazaki, T., 2012. Development of a comprehensive analytical method for semi-volatile organic compounds in sediments by using an automated identification and quantification system with a GC-MS database. Anal. Sci. 28, 1183-1189.

Kadokami, K., Tanada, K., Taneda, K., Nakagawa, K., 2005. Novel gas chromatography-mass spectrometry database for automatic identification and quantification of micropollutants. J. Chromatogr. A 1089, 219-226.

Kolpin, D.W., Furlong, E.T., Meyer, M.T., Thurman, E.M., Zaugg, S.D., Barber, L.B., Buxton, H.T., 2002. Pharmaceuticals, hormones, and other organic wastewater contaminants in U.S. Streams, 1999-2000: a national reconnaissance. Environ. Sci. Technol. 36, 1202-1211.

Li, D., Dong, M., Shim, W.J., Kannan, N., 2007. Application of pressurized fluid extraction technique in the gas chromatography-mass spectrometry determination of sterols from marine sediment samples. J. Chromatogr. A 1160, 64-70.

Long, E.R., MacDonald, D.D., Smith, S.L. Calder, F.D., 1995. Incidence of adverse biological effects within ranges of chemical concentrations in marine and estuarine sediments. Environ. Manag. 19, 81-97.

Lundgren, K., Rappe, C., Tysklind, M., 2004. Low-resolution mass spectrometric relative response factors (RRFs) and relative retention times (RRTs) on two common gas chromatographic stationary phases for 87 polychlorinated dibenzofurans. Chemosphere 55, 983-995.

Navarro, P., Cortazar, E., Bartolomé, L., Deusto, M., Raposo, J.C., Zuloaga, O., Arana, G., Etxebarria, N., 2006. Comparison of solid phase extraction, saponification and gel permeation chromatography for the clean-up of microwave-assisted biological extracts in the analysis of polycyclic aromatic hydrocarbons. J. Chromatogr. A 1128, 10-16.

Pang, G.-F., Cao, Y.-Z., Zhang, J.-J., Fan, C.-L., Liu, Y.-M., Li, X.-M., Jia, G.-Q., Li, Z.-Y., Shi, Y.-Q., Wu, Y.-P., Guo, T.-T., 2006. Validation study on 660 pesticide residues in animal tissues by gel permeation chromatography cleanup/gas chromatography-mass spectrometry and liquid chromatography-tandem mass spectrometry. J. Chromatogr. A 1125, 1-30.

Sauter, A.D., Betowski, L.D., Ballard, J.M., 1983. Comparison of priority pollutant response factors for triple and single quadrupole mass spectrometers. Anal. Chem. 55, 116-119.

Sauter, A.D., Downs, J.J., Buchner, J.D., Ringo, N.T., Shaw, D.L., Dulak, J.G., 1986. Model for the estimation of electron impact gas chromatography/mass spectrometry response factors for quadrupole mass spectrometers. Anal. Chem. 58, 1665-1670.

Sharpe, R.M., 2001. Hormones and testis development and the possible adverse effects of environmental chemicals. Toxicol. Lett. 120, 221-232.

Sharpe, R.M., Irvine, D.S., 2004. How strong is the evidence of a link between environmental chemicals and adverse effects on human reproductive health? Br. Med. J. 328, 447-451.

Turlington, J.M., McDow, S.R., 2010. Solid phase extraction cleanup for non-polar and moderately polar molecular markers of PM2.5 sources. Atmos. Environ. 44, 2161-2165.

USEPA, 1994. EPA Method 3640A Gel-permeation Cleanup. Washington, DC.

Windal, I., Miller, D.J., De Pauw, E., Hawthorne, S.B., 2000. Supercritical fluid extraction and accelerated solvent extraction of dioxins from high- and lowcarbon fly ash. Anal. Chem. 72, 3916-3921.

Zhong, W., Wang, D., Xu, X., Luo, Q., Wang, B., Shan, X., Wang, Z., 2010. Screening level ecological risk assessment for phenols in surface water of the Taihu Lake. Chemosphere 80, 998-1005. 